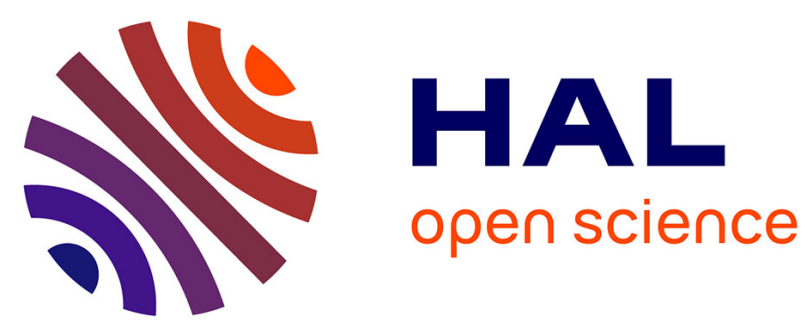

\title{
Pre-hole diameter optimization in high speed drilling considering machining cost
}

Monia Ben Meftah, Maher Baili, Bassem Gassara, Gilles Dessein, Wassila Bouzid Saï

\section{- To cite this version:}

Monia Ben Meftah, Maher Baili, Bassem Gassara, Gilles Dessein, Wassila Bouzid Saï. Pre-hole diameter optimization in high speed drilling considering machining cost. International Journal of Advanced Manufacturing Technology, 2019, 103 (9-12), pp.3323-3336. 10.1007/s00170-019-03689-z . hal-02434406

\section{HAL Id: hal-02434406 https://hal.science/hal-02434406}

Submitted on 10 Jan 2020

HAL is a multi-disciplinary open access archive for the deposit and dissemination of scientific research documents, whether they are published or not. The documents may come from teaching and research institutions in France or abroad, or from public or private research centers.
L'archive ouverte pluridisciplinaire HAL, est destinée au dépôt et à la diffusion de documents scientifiques de niveau recherche, publiés ou non, émanant des établissements d'enseignement et de recherche français ou étrangers, des laboratoires publics ou privés. 


\section{OATAO \\ Open Archive Toulouse Archive Ouverte}

\section{Open Archive Toulouse Archive Ouverte}

OATAO is an open access repository that collects the work of Toulouse researchers and makes it freely available over the web where possible

This is an author's version published in: http://oatao.univ-toulouse.fr/25180

Official URL:

https://doi.org/10.1007/s00170-019-03689-z

\section{To cite this version:}

Ben Meftah, Monia and Baili, Maher and Gassara, Bassem and Dessein, Gilles and Bouzid Saï, Wassila Pre-hole diameter optimization in high speed drilling considering machining cost. (2019) International Journal of Advanced Manufacturing Technology, 103 (9-12). 3323-3336. ISSN 0268-3768

Any correspondence concerning this service should be sent to the repository administrator: tech-oatao@listes-diff.inp-toulouse.fr 


\title{
Pre-hole diameter optimization in high speed drilling considering machining cost
}

\author{
Monia Ben Meftah ${ }^{1} \cdot$ Maher Baili $^{2} \cdot$ Bassem Gassara $^{1} \cdot$ Gilles Dessein $^{2} \cdot$ Wassila Bouzid Saï $^{1}$
}

\begin{abstract}
In this paper, a new methodology of tool diameter optimization in high-speed peck drilling cycle G83 is investigated in order to predict the pre-drill diameters and cutting speed which lead to the minimum cutting cost. In this aim, a pre-drill diameter modeling is proposed. The cycle time is calculated based on a feed rate modeling which depends on the kinematic performance of the machine. To reach higher precision of the predicted results, an optimization algorithm is developed taking into consider-ation the technological and machine constraints (machine power, spindle speed, and feed rate). An experimental study is carried out to validate the feed rate modeling and to calculate the value of the specific cutting force of studied material. To demonstrate the procedure, an illustrative example of AISI 4140 workpiece material is discussed in detail. The obtained results show that the economical process of drilling in peck drilling cycle G83 is obtained with the minimum number of pre-drill diameter.
\end{abstract}

Keywords High speed drilling $\cdot$ Pre-drill diameter $\cdot$ Peck drilling cycle G83 $\cdot$ Machining time $\cdot$ Machining cost $\cdot$ Optimization

$\begin{array}{ll}\text { Nomenclature } \\ T_{m} \quad \text { Total machining time [min] } \\ t_{\mathrm{c}} \quad \text { Time of drilling cycle [min] } \\ t_{\mathrm{r}} & \text { Time of tool movements at the work feed rate [min] } \\ t_{\mathrm{tch}} & \text { Time of tool change [min/tool] } \\ t_{\mathrm{chnt}} & \text { Time of tool change per piece [min] } \\ t_{\mathrm{a}} & \text { Auxiliary time related to the operator [min] }\end{array}$

Monia Ben Meftah

moniabenmeftah56@yahoo.com

Maher Baili

maher.baili@enit.fr

Bassem Gassara

bassem.gassara@enis.tn

Gilles Dessein

gilles.dessein@enit.fr

Wassila Bouzid Saï

wassilabouzid@yahoo.fr

1 Ecole Nationale d'Ingénieurs de Sfax, Unité de Génie de Production Mécanique et Matériaux, Université de Sfax, UR17ES43, 3038 Sfax, Tunisia

2 Laboratoire de Génie de Production, LGP, ENIT, 65000 Tarbes, France $t_{\mathrm{u}} \quad$ The time during which the tool is in contact with the work piece [min]

$T \quad$ The tool life [min]

$t_{\text {chns }} \quad$ The spindle change time per operation [min]

$t_{\text {sch }} \quad$ The spindle change time [min]

$T_{\mathrm{s}} \quad$ The spindle life [min]

$t_{\mathrm{ld}} \quad$ The time of unloading a drill tool and loading another one [min]

$t_{\mathrm{rp}} \quad$ The time of movement at rapid feed rate [min]

$t_{\mathrm{VF}} \quad$ The time of movement at work feed rate [min]

$t_{\mathrm{EF}} \quad$ The total temporization time [min]

$V_{\mathrm{m}} \quad$ Maximum feed rate $\left[\mathrm{mm} \mathrm{min}^{-1}\right]$

$V_{\mathrm{f}} \quad$ The feed rate $\left[\mathrm{mm} \mathrm{min}^{-1}\right]$

$V_{\mathrm{c}} \quad$ The cutting speed $\left[\mathrm{m} \mathrm{min}^{-1}\right]$

$V_{\mathrm{c}_{\mathrm{j}_{\mathrm{c}}}} \quad$ The corrected cutting speed $\left[\mathrm{m} \mathrm{min}^{-1}\right]$

$f \quad$ The feed $[\mathrm{mm} / \mathrm{rev}]$

$f_{\mathrm{j}_{\mathrm{c}}} \quad$ The corrected feed [mm/rev]

$D \quad$ The hole diameter $[\mathrm{mm}]$

$l \quad$ The hole depth [mm]

$l \quad$ The total hole depth [mm]

$\delta \quad$ Point angle $\left[{ }^{\circ}\right]$

$P \quad$ The size of first peck drilling cycle [mm]

$Q \quad$ The size of following peck drilling cycle [mm]

$Q_{\mathrm{f}} \quad$ The last peck drilling [mm]

$n \quad$ The number of peck drilling 


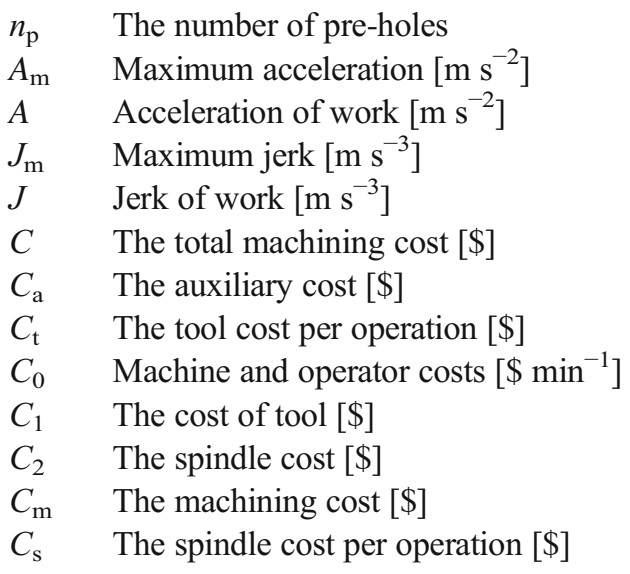

\section{Introduction}

The drilling operation is one of the most important operations in the mechanical production, and many researchers have dealt with the optimization of machining parameters in conventional drilling without pre-hole. However, the total material to be removed to achieve the final hole size is limited by various constraints such as available tool capacity and machine power. Thus, it is crucial to make some pre-hole drilling. In fact, there are a few works on the optimization of drilling operation with pre-hole reported in the literature.

Starting with the works in drilling operation without predrill, Kim and Dornfeld [1] have presented a model to estimate and minimize the cost of drilling operation based on a drilling burr control chart and Bayesian statistics, in which the cost of a drilling operation consists of the cost of drilling (hole making) and the cost of deburring. Kim and Ramulu [2] have optimized the drilling process of graphite/bismaleimidetitanium alloy $(\mathrm{Gr} / \mathrm{Bi}-\mathrm{Ti})$ stacks in terms of machining cost and hole quality used a multiple objective linear program. Iacob et al. [3] have optimized the cutting tool life and the associated cutting speed in the drilling of the stainless steels to minimize the machining cost. Herein, a nonlinear programming model is developed. In the case of drilling operation with pre-drill, Shunmugam et al. [4] have presented an optimization approach of the parameters in drilling with pre-hole (cutting speed, pre-drill diameter) which leads to the minimum production cost considering technological and machine constraints. This model was developed for the case of drilling in conventional machining. The selection of pre-drill diameters is arbitrary. Debongnie [5] has proposed a pre-drill diameter as the one third of the final diameter. Recently, Guiotoko et al. [6] have presented a hole drilling process with pre-drill. This process depends on the final diameter and the selected hole tolerance.

In deep hole drilling, the cutting is carried out at the bottom of the hole so the evacuation of chips from the hole and the discharge of heat at the cutting edge becomes difficult. In this respect, a peck drilling cycle (G83) is used to break and evacuate the chips by the regular retraction movement to a level above the work piece. The movements of retraction tend to increase the cycle time. So, a precise estimation of the machining time becomes necessary. Othmani et al. [7] have presented a model of cutting parameter optimization in NC milling without considering the variation of the feed rate, particularly in peck drilling cycle. But in high speed machining, particularly in drilling, the programmed feed rate is not always reached. The feed rate profile depends on tool path geometry and kinematical parameters of the machine $[8,9]$. This leads to an underestimation of machine time.

In this paper, a methodology of pre-drill diameter optimization in high-speed peck drilling cycle G83 is developed. This methodology based on a pre-drill diameter model which is developed in Section 2. Then, a machining time model is presented in Section 3, in which a feed rate modeling is developed. Section 4 gives a machining cost model. In Section 5, a methodology of pre-drill diameters optimization is proposed. Section 6 shows an experimental study and validation. Finally, Section 7 draws the results and discussions.

The peck drilling cycle G83 is used when a deep hole is being machined [10]; initially the tool moves at rapid feed rate from the A (safe position) to the B (approach plane) (Fig. 1). Then, the tool moves incrementally, and after each incremental distance, the tool retracts to the approach plane. After, it moves for the next incremental distance at rapid feed rate, until $L_{\mathrm{uj}}$ depth is reached (C position).

\section{Pre-drill diameter modeling}

\subsection{The known recommendations and limitations}

In drilling operation, the final hole diameter is obtained by drilling with one or more drills. The number of pre-drill diameter depends on technological constraints, such as final hole size, workpiece material, and tool geometry.

The maximum diameter drilled without pilot drill for the AISI 4140 alloy steel is fixed equal to $20 \mathrm{~mm}$ [6].

Debongnie [5] has proposed a pre-drill diameter as the one third of the final diameter. In this study, the limitation of predill diameter proposed is given by:

$D_{j^{\prime}+1} \geq \frac{D_{\mathrm{j}^{\prime}}}{3}$

The pre-hole diameter is also limited by the geometry of the drill; the drill web thickness $W_{\mathrm{j}^{\prime}}$ must be smaller than the prehole diameter [11] (Fig. 2). The $W_{\mathrm{j}^{\prime}}$ is in the range of 8-12\% of the drill diameter [12]; this limitation is respected in the precedent condition. 
Fig. 1 Peck drill cycle G83 (drilling through hole with a predrill)

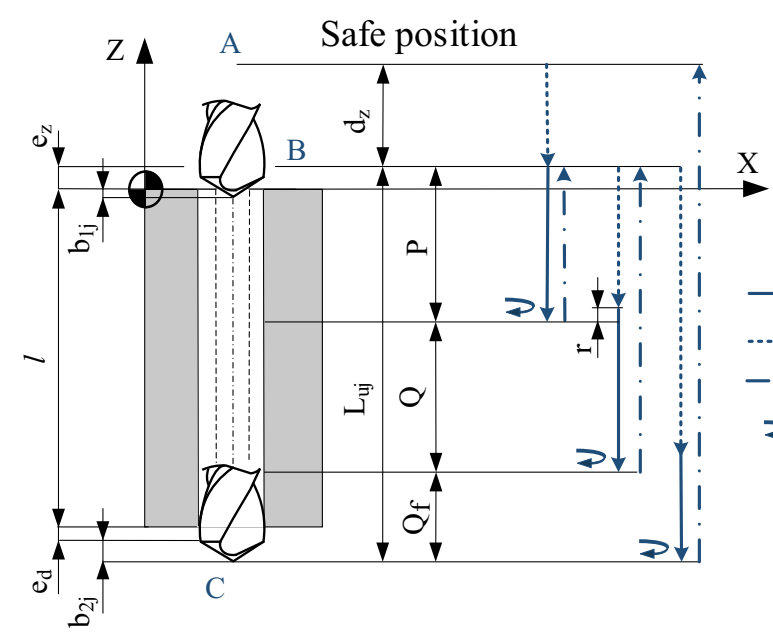

Movement at work feed rate $V_{f}$ Approach at rapid feed rate $V_{r}$ $\rightarrow$ Retraction at rapid feed rate $V_{r}$ $>$ Temporisation

\subsection{The model developed in this work}

The pre-drill diameters $D_{\mathrm{j}^{\prime}}\left(j^{\prime}\right.$ from 1 to $\left.n_{\mathrm{p}}\right)$ are calculated from the final diameter $D$ to the first pre-drill diameter. The using equations are detailed as follows:

$\left\{\begin{array}{ll}\text { If } & \left(D_{\mathrm{j}^{\prime}+1} \leq D_{\mathrm{m}}\right) \\ \text { else } & D_{\mathrm{j}^{\prime}+1}=D_{\mathrm{j}^{\prime}}-d_{\mathrm{j}^{\prime}}\end{array} \quad\right.$ so $\quad D_{\mathrm{j}}=0$

With : $d_{\mathrm{j}^{\prime}}=\operatorname{Int}\left(\frac{100 m}{D_{\mathrm{j}^{\prime}}}\right)$

The value of $D_{\mathrm{m}}$ is given by:

$\begin{cases}D_{\mathrm{m}}=D_{1 \mathrm{~m}} & \text { If }\left(D_{1 m}<20\right) \\ D_{\mathrm{m}}=20 & \text { If not }\end{cases}$
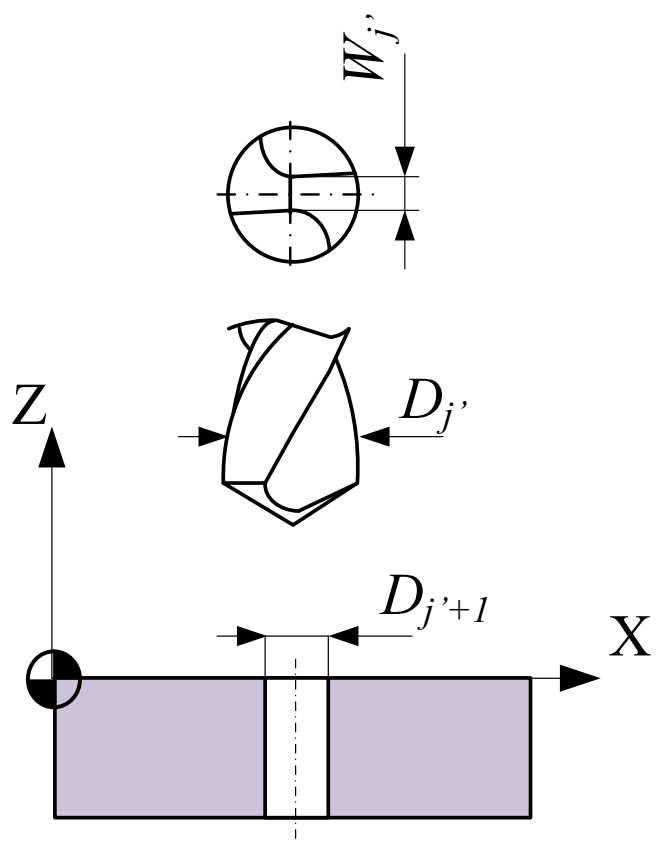

Fig. 2 Drilling with a pre-drill
$D_{1 \mathrm{~m}}$ is calculated as follows:

$D_{1 \mathrm{~m}}=x(3+m)$

where $m$ is a coefficient which depends on tool, workpiece material, and machine specifications (power), $x$ is a constant equal to 3 , and $D_{1 \mathrm{~m}}$ is the maximum hole diameter which can be machined without pre-hole. It depends on the coefficient $m$.

The methodology used for the determination of the different sizes of pre-drill $D_{\mathrm{j}^{\prime}}\left(j^{\prime}=1\right.$ to $\left.n_{\mathrm{p}}\right)$ to obtain the final hole diameter is presented in Fig. 3.

In the following paper, we design the pre-drill diameter by $D_{j}$ with $j$ from 1 to $n_{\mathrm{p}}+1$ is given by: $j=n_{\mathrm{p}}-j^{\prime}+2$. So, the drilling process starts with $D_{1}$ to the final diameter $D_{\mathrm{np}+1}(D)$.

\section{One-hole machining time modeling}

The total machining time $T_{\mathrm{m}}$ for drilling one hole at a final diameter $D_{\mathrm{np}+1}$ with $n_{\mathrm{p}}$ pre-drill diameters $D_{\mathrm{j}}\left(j\right.$ from 1 to $\left.n_{\mathrm{p}}\right)$ is calculated as the sum of each machining time $T_{\mathrm{mj}}$ for drilling a diameter $D_{\mathrm{j}}$, as follows:

$T_{\mathrm{m}}=\sum_{j=1}^{n_{p+1}} T_{\mathrm{m}_{\mathrm{j}}}$

The machining time for drilling a diameter $D_{\mathrm{j}}$ can be composed of six parts as in the expression below:

$T_{\mathrm{m}_{\mathrm{j}}}=t_{\mathrm{c}_{\mathrm{j}}}+t_{\mathrm{r}_{\mathrm{j}}}+t_{\mathrm{ld}_{j}}+t_{\mathrm{chnt}_{\mathrm{j}}}+t_{\mathrm{chns}_{\mathrm{j}}}+\frac{t_{\mathrm{a}}}{n_{\mathrm{p}}+1}$

where:

- $t_{\mathrm{cj}}$ is the drilling cycle time (min),

- $t_{\mathrm{rj}}$ is the time of the approach and retract movement using a rapid feed rate ( $\mathrm{min})$, 
Fig. 3 Algorithm 1 for pre-drill number and size calculation

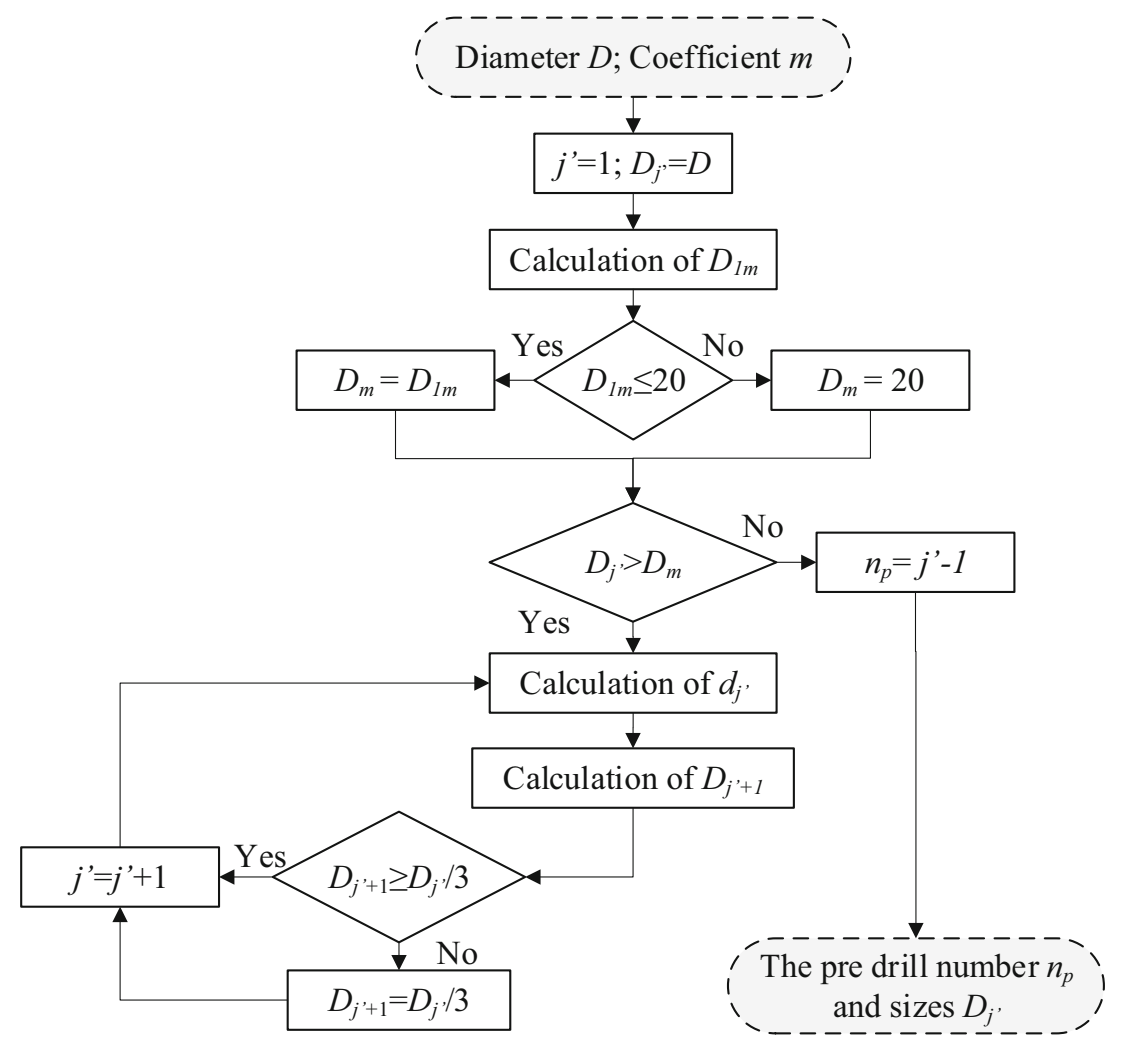

- $\quad t_{\mathrm{ldj}}$ is the time of unloading a drill tool and loading another one, it depends on the characteristics of tool change magazine (min),

- $t_{\text {chntj }}$ is the tool change time when the tool life is reached (min),

- $t_{\text {chnsj }}$ is the spindle change time ( $\mathrm{min}$ ),

- $t_{\mathrm{a}}$ is the non-productive time according to the workpiece and the machine preparation ( $\mathrm{min}$ ).

\subsection{Drilling cycle time $t_{\mathrm{cj}}$}

In high speed drilling, the cycle time depends on the cutting parameters, the tool path geometry, and the kinematic characteristics of the machine.

\subsubsection{Cutting parameters of peck drilling cycle G83}

In drilling, the feed $f_{\mathrm{j}}$ depends on the drill diameter $D_{\mathrm{j}}$ and the material to be removed [13]. It is calculated as follows:

$f_{\mathrm{j}}=k_{\mathrm{f}} D_{\mathrm{j}}^{\mathrm{n}_{\mathrm{f}}}$

where $k_{\mathrm{f}}$ is a constant which depends on the work/piece material and $n_{\mathrm{f}}$ is a constant which depends on the tool material.

For deep holes $\left(l_{\mathrm{j}}^{\prime} \geq 3 D_{\mathrm{j}}\right)$, the feed and the cutting speed used for short drilling are reduced by two correction coefficients, respectively, $\beta_{1}$ and $\beta_{2}$ [13], so:

$f_{\mathrm{j}_{\mathrm{c}}}=\beta_{1} f_{\mathrm{j}}$

$V_{\mathrm{cj}_{\mathrm{c}}}=\beta_{2} V_{\mathrm{c}}$

$\beta_{1}$ and $\beta_{2}$ are the correction coefficients which depend on hole depth $l_{j}^{\prime}$ to diameter $D j$ ratio [13]. Based on the coefficient values, of both $\beta_{1}$ and $\beta_{2}$ proposed by Dietrich et al. [13], the equations of these coefficients are determined as follows:

$\left.\beta_{1}=0.012 \frac{l_{\mathrm{j}}^{\prime}}{D_{\mathrm{j}}}\right)^{2}-0.195 \frac{l_{\mathrm{j}}^{\prime}}{D_{\mathrm{j}}}+1.378$

$\left.\beta_{2}=0.008 \frac{l_{\mathrm{j}}^{\prime}}{D_{\mathrm{j}}}\right)^{2}-0.120 \frac{l_{\mathrm{j}}^{\prime}}{D_{\mathrm{j}}}+1.245$

Total hole depth is given by:

$l_{\mathrm{j}}^{\prime}=l+\frac{D_{\mathrm{j}}-D_{\mathrm{j}-1}}{2 \tan (\delta / 2)}$

\subsubsection{Tool path geometry of deep hole drilling cycle G83}

The drilling cycle (Fig. 1 ) is formed by $3 n_{\mathrm{j}}$ linear blocks which are $n_{\mathrm{j}}$ steps at rapid feed rate, $n_{\mathrm{j}}$ blocks with work feed, and $n_{\mathrm{j}}$ retraction block at rapid feed rate. 
$P_{\mathrm{j}}, Q_{\mathrm{j}}$, and $Q_{\mathrm{fj}}$ are, respectively, the length of the first incremental distance $(\mathrm{mm})$, the following incremental distance $(\mathrm{mm})$, and the last incremental distance $(\mathrm{mm})$.

The total number $n_{\mathrm{j}}$ of incremental distance and the last incremental distance are given by:

$\left\{\begin{array}{lll}\left.n_{\mathrm{j}}=\operatorname{Int} \frac{L_{\mathrm{uj}}-P_{\mathrm{j}}}{Q_{j}}\right)+2 & \text { and } Q_{\mathrm{f}_{\mathrm{j}}}=L_{\mathrm{u}_{\mathrm{j}}}-P_{\mathrm{j}}-\left(n_{\mathrm{j}}-2\right) Q_{\mathrm{j}} & \text { if } \frac{L_{\mathrm{uj}}-P_{\mathrm{j}}}{Q_{\mathrm{j}}} \text { decimal } \\ n_{\mathrm{j}}=\frac{L_{\mathrm{uj}}-P_{\mathrm{j}}}{Q_{\mathrm{j}}}+1 & \text { and } Q_{\mathrm{f}_{\mathrm{j}}}=0 & \text { if not }\end{array}\right.$

where $L_{\mathrm{uj}}$ is expressed as:

$L_{\mathrm{u}_{\mathrm{j}}}=l+e_{\mathrm{z}}+e_{\mathrm{d}}+b_{2_{\mathrm{j}}}$

with $b_{2_{j}}=\frac{D_{j}}{2 \tan (\delta / 2)}$

where $l$ is the depth of the hole, $e_{\mathrm{z}}$ is the approach distance, $e_{\mathrm{d}}$ is the breakthrough distance, and $\delta$ is the drill point angle.

The first and the following incremental distances, respectively, $P_{\mathrm{j}}$ and $Q_{\mathrm{j}}$, depend on the diameter $D_{\mathrm{j}}[5]$ :

$Q_{\mathrm{j}}=P_{\mathrm{j}}=k_{1} D_{\mathrm{j}}$

where $K_{1}$ is a constant depending on the ability to evacuate chips without blocking into the flute which depends on the tool (geometry, Material) and the work piece material; the recommended value is equal to 1 [5].

\subsubsection{Feed rate and drilling cycle time modeling $t_{\mathrm{cj}}$}

Based on the work of Pessoles et al. [8], an analytical study for calculating the feed rate evolution (Fig. 4) according to dynamic performance of machine is detailed.

The model is composed of seven steps (Fig. 4).

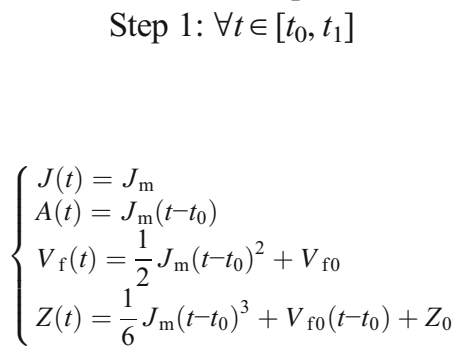

Step 3: $\forall t \in\left[t_{2}, t_{3}\right]$

$\left\{\begin{array}{l}J(t)=-J_{\mathrm{m}} \\ A(t)=-J_{\mathrm{m}}\left(t-t_{2}\right)+J_{\mathrm{m}}\left(t_{1}-t_{0}\right) \\ V_{\mathrm{f}}(t)=-\frac{1}{2} J_{\mathrm{m}}\left(t-t_{2}\right)^{2} \\ +J_{\mathrm{m}}\left(t_{1}-t_{0}\right)\left(t-t_{2}\right)+V f_{2} \\ Z(t)=-\frac{1}{6} J_{\mathrm{m}}\left(t-t_{2}\right)^{3}+\frac{J_{\mathrm{m}}}{2}\left(t_{1}-t_{0}\right) \\ \left(t-t_{2}\right)^{2}+V f_{2}\left(t-t_{2}\right)+Z_{2}\end{array}\right.$

Step 4: $\forall t \in\left[t_{3}, t_{4}\right]$

$\left\{\begin{array}{l}J(t)=0 \\ A(t)=0 \\ V_{\mathrm{f}}(t)=V_{\mathrm{m}} \\ Z(t)=V_{\mathrm{m}}\left(t-t_{3}\right)+Z_{3}\end{array}\right.$

Step 5: $\forall t \in\left[t_{4}, t_{5}\right]$

$$
\left\{\begin{array}{l}
J(t)=-J_{\mathrm{m}} \\
A(t)=-J_{\mathrm{m}}\left(t-t_{4}\right) \\
V_{\mathrm{f}}(t)=-\frac{1}{2} J_{\mathrm{m}}\left(t-t_{4}\right)^{2}+V_{\mathrm{m}} \\
Z(t)=-\frac{1}{6} J_{\mathrm{m}}\left(t-t_{4}\right)^{3}+V_{\mathrm{m}}\left(t-t_{4}\right)+Z_{4}
\end{array}\right.
$$

Step 6: $\forall t \in\left[t_{5}, t_{6}\right]$

$\left\{\begin{array}{l}J(t)=0 \\ A(t)=-A_{\mathrm{m}} \\ V_{\mathrm{f}}(t)=-J_{\mathrm{m}}\left(t_{5}-t_{4}\right)\left(t-t_{5}\right)+V_{\mathrm{f}_{5}} \\ Z(t)=-\frac{1}{2} J_{\mathrm{m}}\left(t_{5}-t_{4}\right)\left(t-t_{5}\right)^{2} \\ +V_{\mathrm{f}_{5}}\left(t-t_{5}\right)+Z_{5}\end{array}\right.$

Step 7: $\forall t \in\left[t_{6}, t_{7}\right]$

Step 2: $\forall t \in\left[t_{1}, t_{2}\right]$

$$
\left\{\begin{array}{l}
J(t)=0 \\
A(t)=A_{\mathrm{m}}=J_{\mathrm{m}}\left(t_{1}-t_{0}\right) \\
V_{f}(t)=A_{\mathrm{m}}\left(t-t_{1}\right)+V_{\mathrm{f}_{1}} \\
Z(t)=\frac{1}{2} A_{\mathrm{m}}\left(t-t_{1}\right)^{2}+V_{\mathrm{f}_{1}}\left(t-t_{1}\right)+Z_{1}
\end{array}\right.
$$

where $J_{\mathrm{m}}$ is the maximum jerk, $A_{\mathrm{m}}$ is the maximum acceleration, $V_{\mathrm{m}}$ is the maximum feed rate, $V_{\mathrm{fo}}$ is the input feed rate, 
Fig. 4 Kinematic profiles for constant jerk

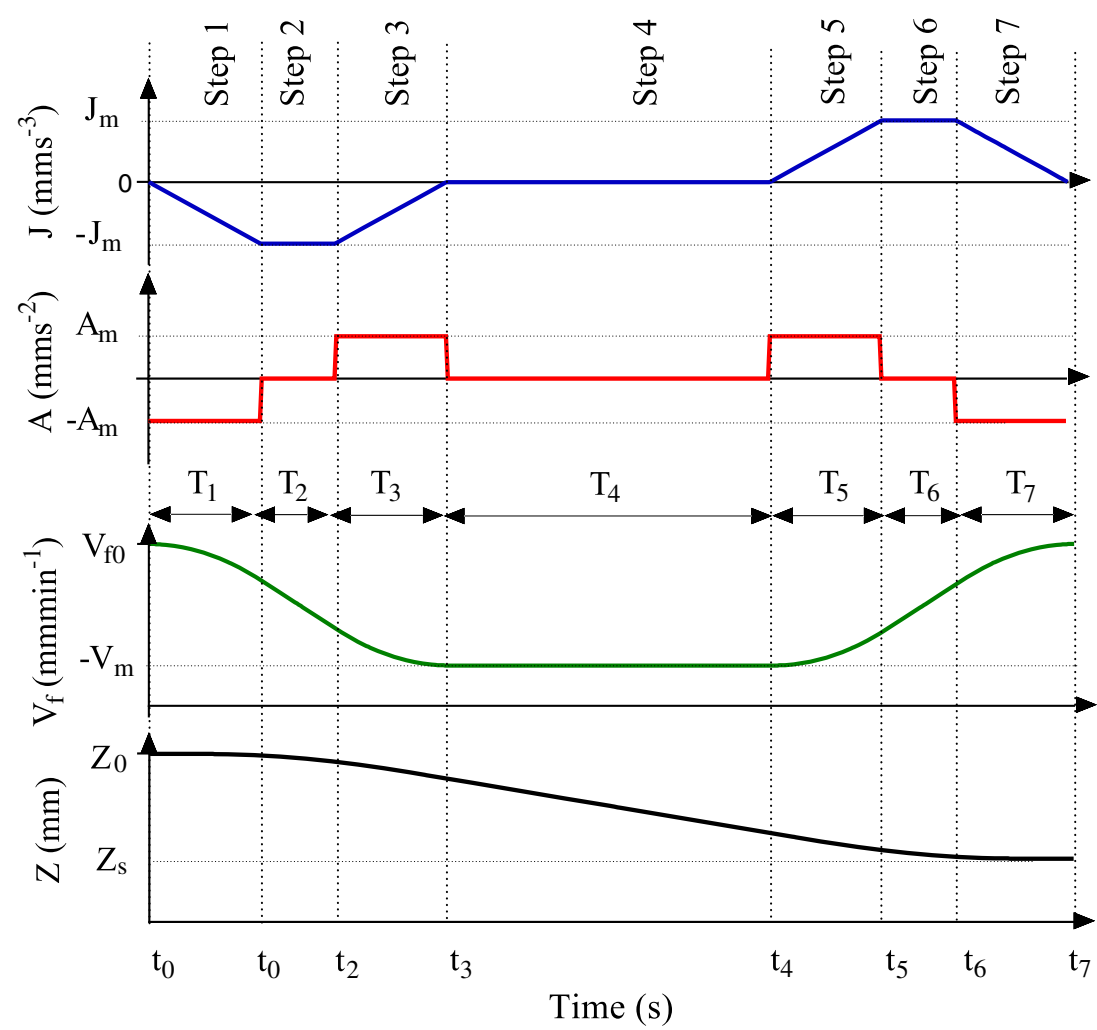

Time (s)
$V_{\mathrm{fs}}$ is the output feed rate, $Z_{0}$ is the input position, and $t_{0}$ is the initial time. The feed rate $V_{\mathrm{fk}}$, the position $Z_{\mathrm{k}}$, and the time $t_{\mathrm{k}}(\mathrm{k}$ from 0 to 6 ) are calculated in terms of the initial input and the duration of each step $T_{\mathrm{k}+1}=t_{\mathrm{k}+1}-t_{\mathrm{k}}(k=0$ à 6$)$.

Depending on kinematic parameters (jerk, programmed feed rate, and the input and output feed rate) and path geometry (path length), some steps of the feed rate curve may disappear. In fact, the programmed feed rate is not always reached, and it will be limited by the length of the block $L$ from which the fourth profile area disappears. Moreover, the disappearance of the second and the sixth steps is related to the low values of the jerk by keeping a sufficient length to reach the maximum feed rate. Pessoles et al. [8] have studied the different cases.

The duration of each step $T_{\mathrm{k}}$ can be calculated by using MATLAB software.

The cycle time $t_{\mathrm{cj}}$ for peck drilling cycle is determined as follows:

$t_{\mathrm{c}_{\mathrm{j}}}=t_{\mathrm{ar}_{\mathrm{j}}}+t_{\mathrm{VF}_{\mathrm{j}}}+t_{\mathrm{re}_{\mathrm{j}}}+t_{\mathrm{EF}_{\mathrm{j}}}$

where:

$t_{\mathrm{EFj}}$ is the total temporization time which depends on the number of the incremental distance:

$t_{\mathrm{EF}_{\mathrm{j}}}=\left(n_{j}-1\right) E F$ $t_{\text {arj }}$ is the total time for approach movement with fast feed rate: $t_{\mathrm{ar}_{\mathrm{j}}}=\sum_{i=0}^{n_{j}-1} \sum_{k=1}^{7} T_{\mathrm{k}_{3 i+1}}$

$t_{\mathrm{VFj}}$ is the total time for the movement with programmed feed rate: $t_{\mathrm{VF}_{\mathrm{j}}}=\sum_{i=0}^{n_{j}-1} \sum_{k=1}^{7} T_{\mathrm{k}_{2 i+1}}$

$t_{\text {rej }} \quad$ is the total time for the retraction movement with fast feed rate: $t_{\mathrm{re}_{\mathrm{j}}}=\sum_{i=1}^{n_{j}} \sum_{k=1}^{7} T_{\mathrm{k}_{3 \mathrm{i}}}$

The time $t_{\mathrm{uj}}$ during which the tool is in contact with the work piece is calculated as follows:

$t_{\mathrm{u}_{\mathrm{j}}}=t_{\mathrm{VF}_{\mathrm{j}}}-t_{\mathrm{ap}_{\mathrm{j}}}$

where $t_{\text {apj }}$ is the time of approach and the breakthrough movement with programmed feed rate; it is calculated using feed rate modeling by summing the time during the approach movement which corresponds to the first approach distance $e_{\mathrm{z}}$, the following approach distance $r$, and the breakthrough distance $e_{\mathrm{d}}$ (Fig. 1).

\subsection{Time of the approach and retract rapid movement $t_{\mathrm{r}}$}

In the approach and retract movement, the tool path is represented by a linear contour $(M A)$ (Fig. 5).where $X_{\mathrm{M}}, Y_{\mathrm{M}}$, and $Z_{\mathrm{M}}$ are the point $M$ coordinates and $X_{\mathrm{A}}, Y_{\mathrm{A}}$, and $Z_{\mathrm{A}}$ are the 


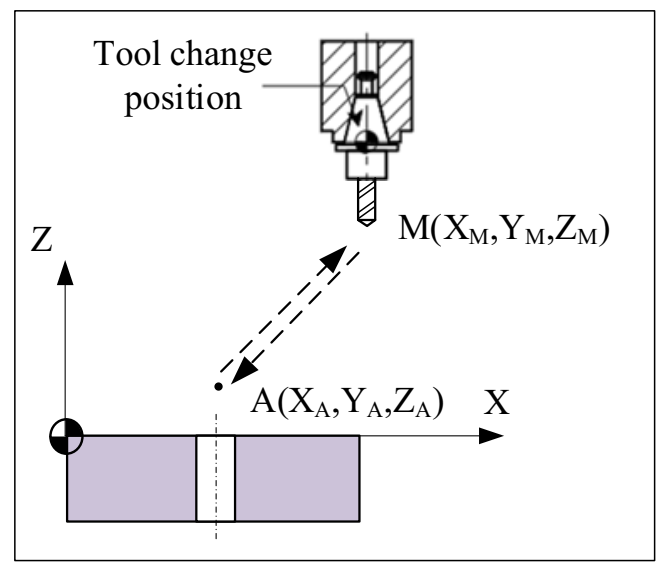

Fig. 5 Rapid movement

point $A$ coordinates. The time is calculated by using the feed rate modeling with the rapid feed rate $V_{\mathrm{r}}$. The distance value of the linear contour $(M A)$ is given by:

$M A=\sqrt{\left(X_{\mathrm{M}}-X_{\mathrm{A}}\right)^{2}+\left(Y_{\mathrm{M}}-Y_{\mathrm{A}}\right)^{2}+\left(Z_{\mathrm{M}}-Z_{\mathrm{A}}\right)^{2}}$

The time of the approach and retract rapid movement $t_{\mathrm{r}}$ is calculated as follows:

$t_{\mathrm{r}_{\mathrm{j}}}=2 \sum_{k=1}^{7} T_{\mathrm{k}}$

\subsection{Tool change time $t_{\text {chntj }}$}

The tool change time per hole $t_{\text {chntj }}$ is calculated in relation to tool life:

$t_{\text {chnt }_{\mathrm{j}}}=t_{\text {tch }_{\mathrm{j}}} \frac{t_{\mathrm{uj}}}{T_{\mathrm{j}}}$

where $t_{\text {tchj }}$ is the drill change time ( $\mathrm{min} /$ tool), $t_{\mathrm{uj}}$ is the time during which the tool is in contact with the work piece (min), and $T_{\mathrm{j}}$ is the tool life (min) calculated according to the model of Shunmugam et al. [4]:

$T_{\mathrm{j}}=C V_{c j_{c}}^{n} f_{j_{c}}^{x} D_{j}^{y}\left(\frac{D_{\mathrm{j}}-D_{\mathrm{j}-1}}{2}\right)^{z}$

$C, n, x, y, z$ are the tool life coefficients which depend on the tool and work piece material, whose values, in the case of drilling the AISI 4340 with carbide drill, are shown in Table 1.

Table 1 Taylor's coefficients $[4,14]$

\begin{tabular}{llllll}
\hline Coefficient & $C$ & $n$ & $x$ & $y$ & $Z$ \\
\hline Direct drilling & 6.988 & -2.165 & -2.5 & 2 & 0 \\
Drilling with pre-hole & 69.88 & -2.165 & -2.5 & 2 & -1 \\
\hline
\end{tabular}

\subsection{Spindle change time $t_{\text {chnsj }}$}

The Spindle change time $t_{\text {chnsj }}$ for drilling one hole at a diameter $D_{\mathrm{j}}$ is calculated in relation to the tool life:

$t_{\text {chnt }_{\mathrm{j}}}=t_{\mathrm{sch}} \frac{t_{\mathrm{uj}}}{T_{\mathrm{s}}}$

where $t_{\text {sch }}$ is the spindle change time ( $\left.\mathrm{min} / \mathrm{spindle}\right)$ and $T_{\mathrm{s}}$ is the spindle life (min). $T_{\mathrm{s}}$ varies from 5000 and 10,000 $\mathrm{h} \mathrm{[15].}$

\section{Total one-hole machining cost modeling}

The total machining cost $C$ for drilling one hole at a final diameter $D_{\mathrm{np}+1}$ with $n_{\mathrm{p}}$ pre-drills diameters $D_{\mathrm{j}}$ (j from 1 to $n_{\mathrm{p}}$ ) is calculated as the sum of each machining cost $C_{\mathrm{j}}$ for drilling a diameter $D_{\mathrm{j}}$, and it is expressed as follows:

$C=\sum_{j=1}^{n_{\mathrm{p}+1}} C_{\mathrm{j}}$

The machining cost for drilling a diameter $D_{\mathrm{j}}$ can be composed of four parts as in the below expression:

$C_{\mathrm{j}}=\frac{C_{\mathrm{a}}}{n_{\mathrm{p}+1}}+C_{\mathrm{t}_{\mathrm{j}}}+C_{\mathrm{s}_{\mathrm{j}}}+C_{\mathrm{m}_{\mathrm{j}}}$

where:

$C_{\mathrm{a}}$ is the auxiliary cost (\$), it is attached to the machine and workpiece preparation.

- $C_{\mathrm{tj}}$ is the tool cost (\$), calculated by:

$C_{\mathrm{t}_{\mathrm{j}}}=\left(C_{1_{\mathrm{j}}}+C_{0} t_{\mathrm{tch}_{\mathrm{j}}}\right) \frac{t_{\mathrm{uj}}}{T_{\mathrm{j}}}$

Where $C_{1 \mathrm{j}}$ is the price of the tool (\$), $C_{0}$ is the machine cost $\left(\$ \min ^{-1}\right)$,

- $C_{\mathrm{sj}}$ is the spindle cost per piece (\$), it is given by:

$C_{\mathrm{s}_{\mathrm{j}}}=\left(C_{2}+C_{0} t_{\mathrm{sch}}\right) \frac{t_{\mathrm{uj}}}{T_{\mathrm{s}}}$

With $C_{2}$ is the spindle cost (\$),

- $C_{\mathrm{mj}}$ is the machining cost related to the machine cost, it is given by:

$C_{\mathrm{m}_{\mathrm{j}}}=C_{0}\left(t_{\mathrm{c}_{\mathrm{j}}}+t_{r_{j}}+t_{\mathrm{ld}_{\mathrm{j}}}\right)$ 


\section{Optimization of pre-drill diameters}

\subsection{Constraints}

The cutting parameters values are limited by the machine tool constraints such as spindle speed, feed rate and power.

\subsubsection{Spindle speed and feed rate}

The feed $f_{\text {jc }}$ and the cutting speed $V_{\text {cjc }}$ are limited by the admissible spindle speed of the machine $N_{\text {ad }}$ and the maximum axes feed rate $V_{\max }$ as follows:

$V_{\mathrm{cj}_{\mathrm{c}}} \leq V_{\mathrm{cad}_{\mathrm{j}}}=\frac{\pi D_{j}}{1000} N_{\mathrm{ad}}$

$V_{\mathrm{cj}_{\mathrm{c}}} \leq V_{\mathrm{cm}_{\mathrm{j}}}=\frac{\pi D_{\mathrm{j}}}{1000 f_{\mathrm{j}_{\mathrm{c}}}} V_{\max }$

\subsubsection{Machine power}

The cutting power $P_{\text {cj }}$ should not exceed the maximum value of the available machine power transmitted to the cutting tool $P_{\text {cmax }}$ :

$P_{\mathrm{cj}} \leq P_{\mathrm{cmax}}=\frac{\eta}{c_{\mathrm{s}}} P_{\mathrm{M}}$

$\eta$ is the machine efficiency, $P_{\mathrm{M}}$ is the nominal motor power, and $c_{\mathrm{s}}$ is the safety coefficient which equal to 1.7 [3].

In drilling with a pilot hole, the value of cutting power is given by:

$P_{\mathrm{c}_{j}}=\frac{K_{\mathrm{cj}_{\mathrm{j}}} f_{\mathrm{j}_{\mathrm{c}}} V_{\mathrm{cj}_{\mathrm{c}}}}{240}\left(D_{\mathrm{j}}-D_{\mathrm{j}-1}\right)$

In direct drilling, the value of $D_{\mathrm{j}-1}$ is equal to zero.

With $K_{c j}$ is the specific force which is defined as in the model:

$K_{\mathrm{cj}}=A f_{j c}^{n_{1}} V_{c j c}^{n_{2}}$

$A, n_{1}$, and $n_{2}$ are constant.

So:

$P_{c_{j}}=\frac{A f_{\mathrm{jc}}^{n_{1}+1} V_{\mathrm{cjc}}^{n_{2}+1}}{240}\left(D_{\mathrm{j}}-D_{\mathrm{j}-1}\right)$

and:

$P_{\text {cjmax }}=\frac{A f_{\mathrm{jc}}^{n_{1}+1} V_{\mathrm{cjmax}}^{n_{2}+1}}{240}\left(D_{\mathrm{j}}-D_{\mathrm{j}-1}\right)=\frac{\eta}{c_{\mathrm{s}}} P_{\mathrm{M}}$
The maximum speed $V_{\text {cj max }}$ is given by:

$V_{c j \max }=\sqrt[n 2+1]{\frac{240 P_{M} \eta}{A f_{j c}^{n_{1}+1}\left(D_{j}-D_{\mathrm{j}-1}\right) c_{s}}}$

\subsection{Optimization}

The objective of the optimization is to determine the drill sizes and the cutting speed $V_{\text {cej }}$ for each tool which lead to the minimum machining cost. In this study, the proposed method is based on the model of the pre-drill diameter, and it is defined in two steps. In the first step, for different coefficient $m$ (from $m_{0}=1$ to $\left.m_{\max }=6\right)$, the pre-hole diameters $D_{\mathrm{j}}\left(j=1\right.$ to $\left.n_{\mathrm{p}}\right)$ are predicted from the Algorithm 1 (Fig. 3). Then, for each diameters $D_{\mathrm{j}}$, the economical cutting speed $V_{\text {cej }}$ are determined. Afterwards, the used cutting speed $V_{c j}$ are predicted as following:

$V_{\mathrm{cj}}=\min \left(V_{\text {cej }}, V_{\text {cadj }}, V_{\text {cmj }}, V_{\text {cmax j }}\right)$

For each drill diameter $D_{\mathrm{j}}$, the cutting $\operatorname{cost} C_{\mathrm{j}}$ is calculated according to the value of the selected cutting speed $V_{\mathrm{cj}}$. The total cutting cost $C$ for each coefficient $m$ is determined as the

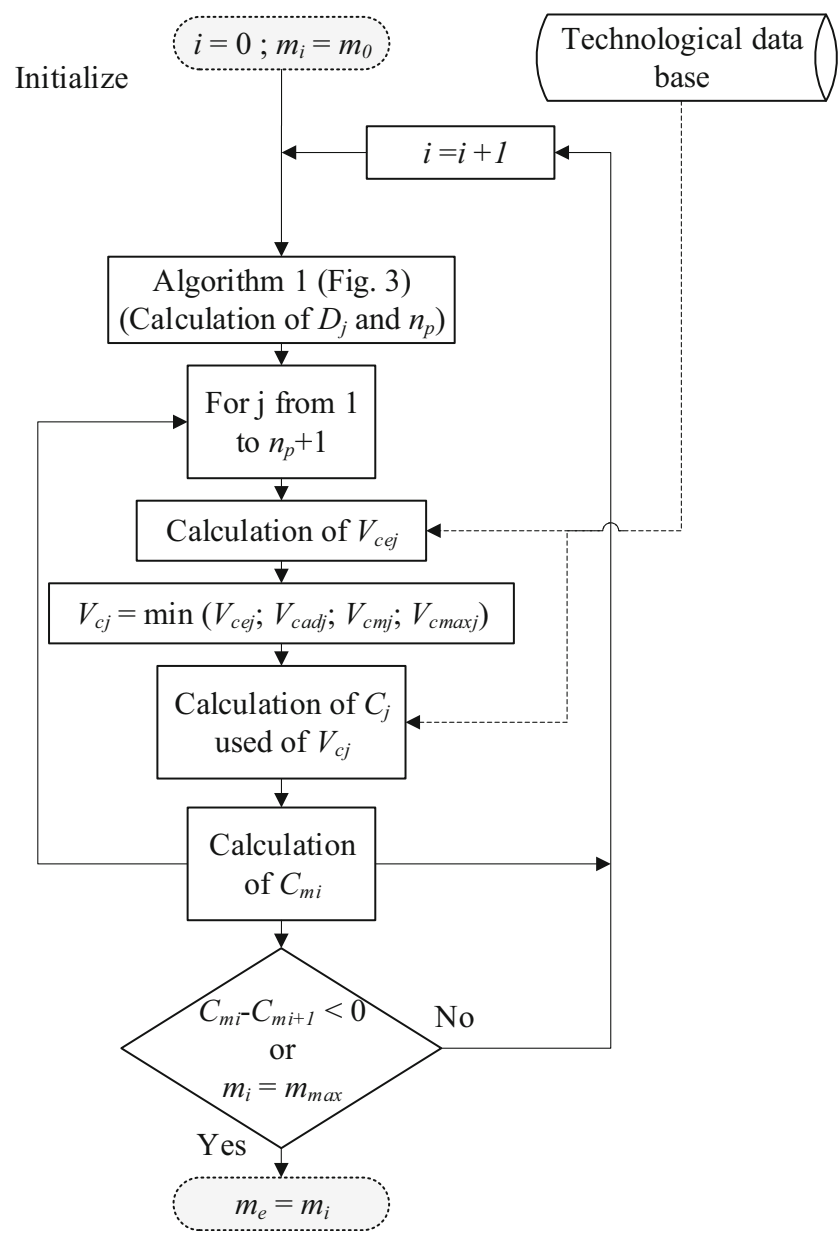

Fig. 6 Algorithm 2 of searching for optimum pre-drill diameters 
Table 2 Machine characteristics

\begin{tabular}{lll} 
Huron Kx10 & \\
\hline Spindle: & Maximum power: & $20 \mathrm{~kW}$ \\
& Spindle speed: & 100 à $24,000 \mathrm{rev} / \mathrm{min}$ \\
& The machine efficiency $(\eta)$ & 0.9 \\
Axis capacity: & Maximum fast speed XY: & $30 \mathrm{~m} / \mathrm{min}$ \\
& Maximum fast speed $Z:$ & $18 \mathrm{~m} / \mathrm{min}$ \\
& Maximum acceleration: & $3 \mathrm{~m} / \mathrm{s}^{2}$ \\
& Jerk maxi: & $50 \mathrm{~m} / \mathrm{s}^{3}$ \\
\hline
\end{tabular}

Table 3 Work piece and tool characteristics

\begin{tabular}{lll}
\hline Work piece & Work piece material & AISI 4140 alloy steel \\
& Hole final diameter $(\mathrm{mm})$ & 16 \\
\multirow{2}{*}{ Tool } & The length of the hole, $l(\mathrm{~mm})$ & 56 \\
& Tool drill material & Carbide drill \\
& The drill point angle, $\delta$ & $140^{\circ}$ \\
\hline
\end{tabular}

sum of the cutting $\operatorname{cost} C_{\mathrm{j}}$. In the second step, the used coefficient $m$ that leads to the minimum cutting cost is predicted. Figure 6 depicts the algorithm of the described procedure.

\section{Experimental study and validation}

In order to validate the feed rate models and examining the torque and thrust force generated during cycle drilling operation, an experimental study was carried on a high speed machine (Table 2). AISI 4140 steel workpiece of 100-mm diameter with a length of $60 \mathrm{~mm}$ is used. The drill tool is a carbide drill Guhring type.

The drilling thrust force was measured by a Kistler cutting force dynamometer (type 9272).

Fig. 7 Variation of the torque $M_{\mathrm{z}}$ $\left(V_{\mathrm{c}}=55.82 \mathrm{~m} / \mathrm{min} ; f=0.118 \mathrm{~mm} /\right.$ rev; $D_{1}=10 \mathrm{~mm} ; D_{2}=16 \mathrm{~mm}$; $P=Q=8 \mathrm{~mm} ; l=56 \mathrm{~mm})$

\subsection{Work piece and tool characteristics}

The work piece and tool characteristics are shown in Table 3.

\subsection{Drilling forces}

An examination of the cutting torque $M_{\mathrm{z}}$ (Fig. 7) indicates that when drilling deep holes, the torque $M_{\mathrm{z}}$ increases as drilling progresses deeper into the work piece. This increase is due to margin rubbing and the chips rubbing with the wall of the drilled hole; it is also caused by the chip thickening [16]. In our study, the safety coefficient $c_{\mathrm{s}}$ takes into account this increase in the prediction of the available machining power.

Tables 4 and 5 show the measured torque $M_{\mathrm{zj}}$ and the specific cutting force $K_{\mathrm{cj}}$ that is calculated by:

$K_{\mathrm{c}_{\mathrm{j}}}=8 \frac{M_{\mathrm{z}_{\mathrm{j}}}}{\left(D_{\mathrm{j}}^{2}-D_{\mathrm{j}-1}^{2}\right) f_{\mathrm{j}_{\mathrm{c}}}}$

The equations of the specific cutting force were obtained through the ANOVA regression analysis using the results shown in Tables 4 and 5, and it is expressed as follows:

- For direct drilling:

$K_{\mathrm{c}_{\mathrm{j}}}=1379.648 f_{\mathrm{jc}}^{-0.4} V_{\mathrm{c}_{\mathrm{jc}}}^{-0.03}$

- For drilling with a pilot hole:

$K_{\mathrm{c}_{\mathrm{j}}}=878.77 f_{\mathrm{jc}}^{-0.563} V_{\mathrm{c}_{\mathrm{jc}}}^{-0.004}$

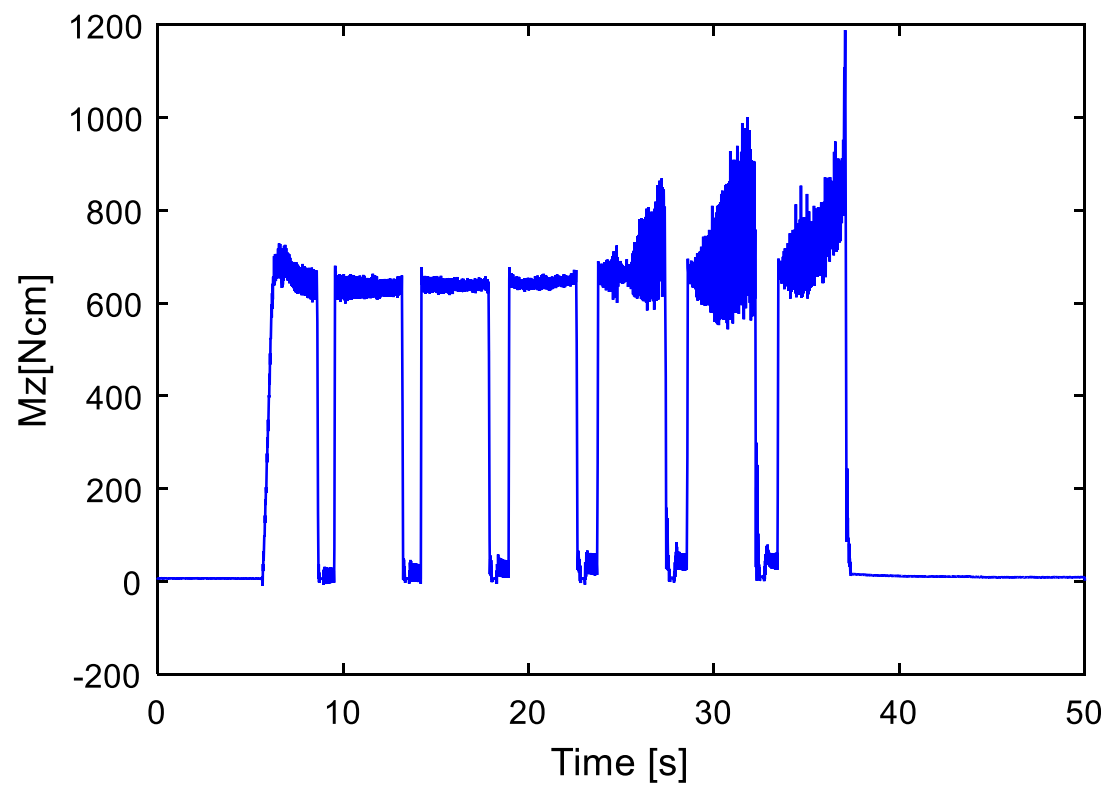


Table 4 Experimental torque $M_{\mathrm{Z}}$ (direct drilling)

\begin{tabular}{lllllllll}
\hline Test & $K_{1}$ & $D_{\mathrm{j}}(\mathrm{mm})$ & $D_{\mathrm{j}-1}(\mathrm{~mm})$ & $Q(\mathrm{~mm})$ & $V_{\mathrm{cjc}}(\mathrm{m} / \mathrm{min})$ & $f_{\mathrm{jc}}(\mathrm{mm} / \mathrm{tr})$ & $M_{\mathrm{z}}(\mathrm{Nm})$ & $K_{\mathrm{c}}\left(\mathrm{N} / \mathrm{mm}^{2}\right)$ \\
\hline 1 & 1.25 & 8 & 0 & 10 & 79.70 & 0.05 & 1.640 & 4270.80 \\
2 & 0.5 & 10 & 0 & 5 & 49.43 & 0.06 & 3.120 & 3902.50 \\
3 & 1 & 10 & 0 & 10 & 65.91 & 0.06 & 2.598 & 3247.50 \\
4 & 1.25 & 16 & 0 & 20 & 93.30 & 0.12 & 10.817 & 2914.06 \\
\hline
\end{tabular}

Table 5 Experimental results (drilling with a pre-drill)

\begin{tabular}{lllllllll}
\hline Test & $K_{1}$ & $D_{\mathrm{j}}(\mathrm{mm})$ & $D_{\mathrm{j}-1}(\mathrm{~mm})$ & $Q(\mathrm{~mm})$ & $V_{\mathrm{cjc}}(\mathrm{m} / \mathrm{min})$ & $f_{\mathrm{jc}}(\mathrm{mm} / \mathrm{tr})$ & $M_{\mathrm{z}}(\mathrm{Nm})$ & $K_{\mathrm{c}}\left(\mathrm{N} / \mathrm{mm}^{2}\right)$ \\
\hline 5 & 1.25 & 12 & 8 & 15 & 86.48 & 0.08 & 2.939 & 2986.78 \\
6 & 1 & 13 & 10 & 13 & 70.70 & 0.10 & 2.561 & 2886.44 \\
7 & 1 & 16 & 13 & 16 & 74.61 & 0.12 & 3.783 & 2649.15 \\
8 & 1.25 & 16 & 12 & 20 & 93.18 & 0.12 & 4.677 & 2477.22 \\
9 & 0.5 & 16 & 10 & 8 & 55.82 & 0.118 & 6.627 & 2880.17 \\
\hline
\end{tabular}

\subsection{Cycle time and feed rate}

Figure 8 shows the experimental and theoretical feed rate evolution for deep hole cycle G83. It presents a good correlation between experimental and theoretical results.

\section{Results and discussion}

\subsection{Numerical data for the illustrative example}

The numerical parameters and the tool cost used in the application example are shown in Tables 6 and 7 respectively.

\subsection{Pre-hole number in relation to $\mathrm{m}$ coefficient}

Figure $9 \mathrm{a}$ and $\mathrm{b}$ give the number and the size of several pre-hole drill diameters $D_{\mathrm{j}}$ to obtain a final hole diameter respectively in the case of a coefficient $m$ equal to 2 and 5. They show that the number of pre-drill increases with the small number of coefficient $m$. For example, in the drilling of the final diameter $D$ equal to $25 \mathrm{~mm}$, the use of a coefficient $m$ equal to 2 may be preceded by drilling of two pre-drill $\left(D_{1}=6 \mathrm{~mm}, D_{2}=17 \mathrm{~mm}\right)$; however, the use of a coefficient $m$ equal to 5 leads to only one pre-drill $\left(D_{1}=8 \mathrm{~mm}\right)$.

Fig. 8 Feed rate variation during a peck drill cycle $\mathrm{G} 83\left(V_{\mathrm{c}}=\right.$ $55.822 \mathrm{~m} / \mathrm{min}, l=56 \mathrm{~mm} ; f=$ $0.118 \mathrm{~mm} / \mathrm{rev}, D_{2}=16 \mathrm{~mm}, D_{1}=$ $10 \mathrm{~mm}, P=Q=8 \mathrm{~mm}, V_{\mathrm{r}}=$ $\left.18,000 \mathrm{~mm} / \mathrm{min} ; t_{\mathrm{c}}=32.64 \mathrm{~s}\right)$

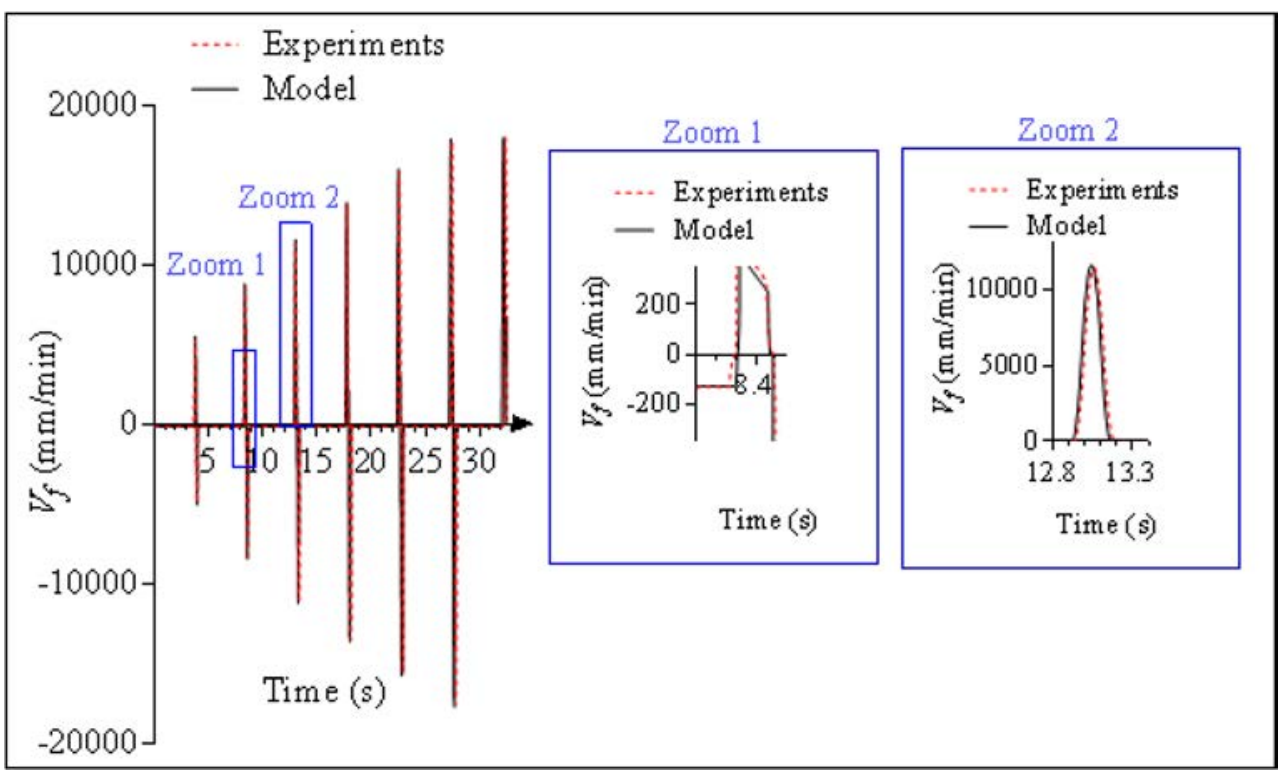


Table 6 Numerical parameters

\begin{tabular}{ll} 
Tool change time, $t_{\mathrm{tch}}(\mathrm{min} / \mathrm{tool})$ & 5 \\
The time of unloading and loading tool, $t_{\mathrm{ldj}}(\mathrm{s})$ & 10 \\
The spindle change time, $t_{\mathrm{sch}}(\mathrm{min} / \mathrm{spindle})$ & 60 \\
The non-productive time, $t_{\mathrm{a}}(\mathrm{min})$ & 1 \\
The spindle life, $T_{\mathrm{s}}(\mathrm{h})$ & 10,000 \\
The non-productive time related to the auxiliary, $t_{\mathrm{a}}(\mathrm{min})$ & 1 \\
The overhead cost, $C_{0}\left(\$ \mathrm{~min}^{-1}\right)$ & 2 \\
The auxiliary cost, $C_{\mathrm{a}}(\$)$, & 1 \\
The spindle cost, $C_{\mathrm{s}}(\$)$ & 24,000 \\
Coefficient, $K_{1}$ & 1 \\
The length of the hole, $l(\mathrm{~mm})$ & 56 \\
The constant, $k_{\mathrm{f}}$ & 0.025 \\
The constant, $n_{\mathrm{f}}$ & 0.76 \\
The safety coefficient, $c_{\mathrm{s}}$ & 1.7 \\
\hline
\end{tabular}

Table 7 Tool cost $C_{1}$

\begin{tabular}{ll}
\hline Tool length & Tool cost, $C_{1}(\$)$ \\
\hline$\leq 3 D_{\mathrm{j}}$ & $C_{1}=0.5\left(0.464 D_{\mathrm{j}}^{2}-5.980 D_{\mathrm{j}}+36.860\right)$ \\
$>3 D_{\mathrm{j}}$ and $\leq 5 D_{\mathrm{j}}$ & $C_{1}=0.5\left(0.867 D_{\mathrm{j}}^{2}-11.280 D_{\mathrm{j}}+69.300\right)$ \\
$>5 D_{\mathrm{j}}$ and $\leq 12 D_{\mathrm{j}}$ & $C_{1}=0.5\left(1.388 D_{\mathrm{j}}^{2}-17.950 D_{\mathrm{j}}+110.600\right)$ \\
\hline
\end{tabular}

\subsection{Total cost and time of one-hole drilling}

\subsubsection{Drilling without pre-hole}

Figures 10 and 11 present respectively the time and the cost evolution with cutting speed for different values of the drill diameter in the case of drilling without pre-hole. So, we can determine the optimal $V_{\text {co }}$ and economical $V_{\text {ce }}$ value of cutting speed for each diameter. It can be concluded that during one-hole drilling with a single drill, the optimal and economical cutting speed decrease by increasing the value of the drill diameter.

\subsubsection{Drilling with pre-hole}

In this section, the time evolution and cost evolution function of cutting speed under different drilling final hole sizes are presented (Figs. 12 and 13). The impact of the coefficient $m$ on the machining time, machining cost, and cutting speed selection in drilling of the final diameter $D_{\mathrm{np}+1}$ can be determined. For each diameter $D_{\text {np }+1}$, the machining time and cost increase with the increase of coefficient $m$, and it is due to the impact of the increase of the width of cut $d$ on the tool life. However, the optimal cutting speed $V_{\text {co }}$ and the economical cutting speed $V_{\text {ce }}$ decrease with the increase of the coefficient $\mathrm{m}$.

\subsection{Pre-hole diameter optimization}

The results predicted using the developed model are listed in Table 8 . The economical values of cutting parameters such as feed and speed are obtained considering the machine constraints. These results permit, firstly, to determine the economic value of the coefficient $m$ (size of the pilot drill) then the economical speed used for drilling such pilot hole. For example, in the case of drilling of a 22-mm diameter hole, the minimal machining cost is obtained when drilling a pre-hole of $1-\mathrm{mm}$ diameter with a cutting speed of $71.32 \mathrm{~m} / \mathrm{min}$ and a final diameter with a cutting speed of $50 \mathrm{~m} / \mathrm{min}$. In our illustrative example, the machining regimes are always covered by the data of the machine tool used.

Clearly, Fig. 14 provides a sufficient approximation to the true optimal coefficient $m$ that leads to the minimal machining cost. It is noted that, although the satisfaction of drill tool life with the multiplication of pre-drill number, the minimum machining cost is obtained with the minimum tool number by reason of the significant increase of the machine cost in peck drilling cycle.
Fig. 9 Pre-hole diameters according to final diameter: $\mathbf{a} m=$ $2 ; \mathbf{b} m=5$
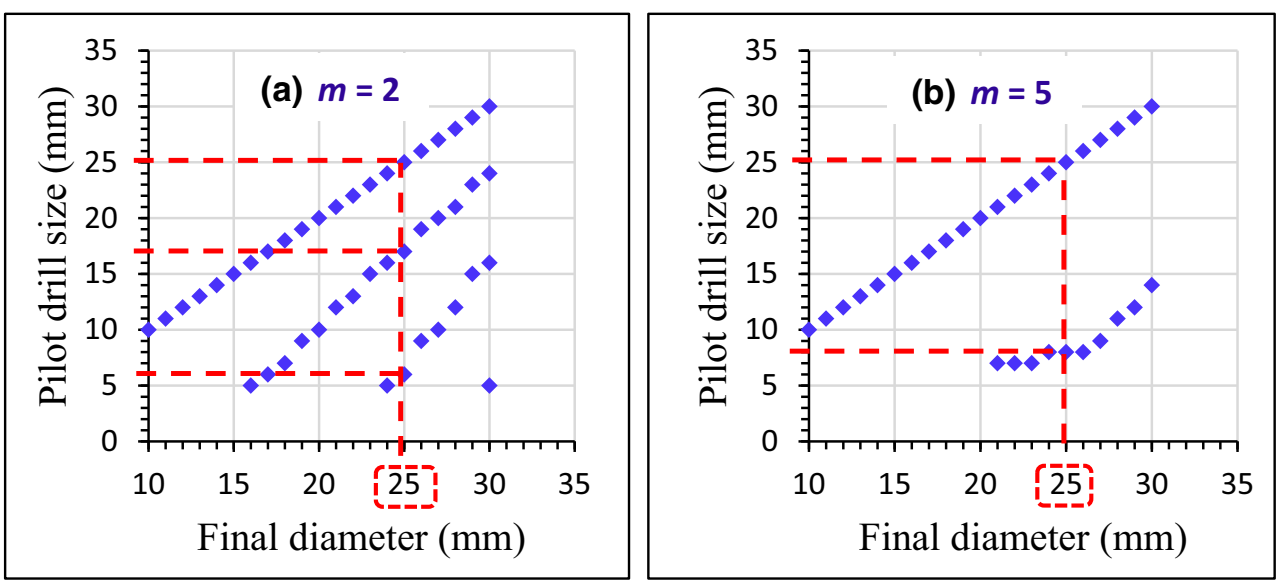
Fig. 10 Cutting time variation with the cutting speed for different diameter $D(d=D$; without pre-hole)

Fig. 11 Total cutting cost variation with the cutting speed for different diameters $D(d=D$; without pre-hole)

Fig. 12 Cutting time and cost variation for drilling the final diameter $D_{\mathrm{np}+1}\left(D_{\mathrm{np}+1}=22 \mathrm{~mm}\right)$

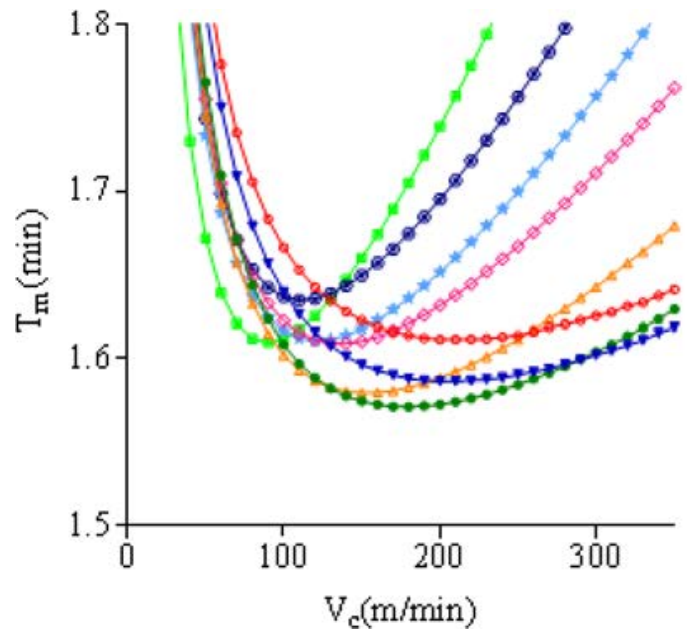

$\therefore \mathrm{D}=6 \mathrm{~mm}, \mathrm{~V}_{\mathrm{co}}=159.40 \mathrm{~m} / \mathrm{min}$

$\rightarrow \mathrm{D}=8 \mathrm{~mm}, \mathrm{~V}_{\mathrm{co}}=158.60 \mathrm{~m} / \mathrm{min}$

$\rightarrow \mathrm{D}=10 \mathrm{~mm}, \mathrm{~V}_{\mathrm{co}}=147.47 \mathrm{~m} / \mathrm{min}$

$\because \mathrm{D}=12 \mathrm{~mm}, \mathrm{~V}_{\mathrm{co}}=133.18 \mathrm{~m} / \mathrm{min}$

$\multimap \mathrm{D}=14 \mathrm{~mm}, \mathrm{~V}_{\mathrm{co}}=120.55 \mathrm{~m} / \mathrm{min}$

\# $\mathrm{D}=16 \mathrm{~mm}, \mathrm{~V}_{\mathrm{co}}=111.68 \mathrm{~m} / \mathrm{min}$

- $\mathrm{D}=18 \mathrm{~mm}, \mathrm{~V}_{\mathrm{co}}=106.29 \mathrm{~m} / \mathrm{min}$

$\because \mathrm{D}=20 \mathrm{~mm}, \mathrm{~V}_{\mathrm{co}}=90.00 \mathrm{~m} / \mathrm{min}$

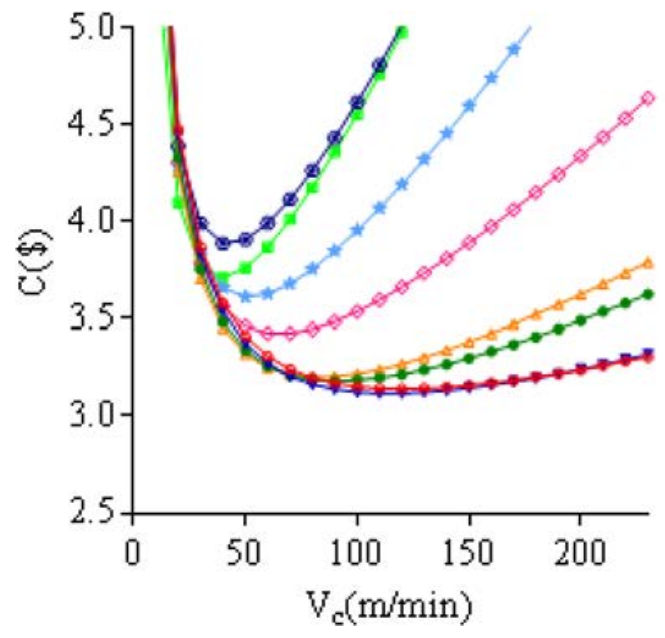

$\rightarrow \mathrm{D}=6 \mathrm{~mm}, \mathrm{~V}_{\mathrm{ce}}=97.23 \mathrm{~m} / \mathrm{min}$

$\rightarrow \mathrm{D}=8 \mathrm{~mm}, \mathrm{~V}_{\mathrm{ce}}=92.45 \mathrm{~m} / \mathrm{min}$

$\rightarrow \mathrm{D}=10 \mathrm{~mm}, \mathrm{~V}_{\mathrm{ce}}=76.62 \mathrm{~m} / \mathrm{min}$

$\because \mathrm{D}=12 \mathrm{~mm}, \mathrm{~V}_{\mathrm{ce}}=71.31 \mathrm{~m} / \mathrm{min}$

$\rightarrow D=14 \mathrm{~mm}, V_{c e}=58.05 \mathrm{~m} / \mathrm{min}$

* $D=16 \mathrm{~mm}, \mathrm{~V}_{\mathrm{ce}}=50.00 \mathrm{~m} / \mathrm{min}$

- $\mathrm{D}=18 \mathrm{~mm}, \mathrm{~V}_{\mathrm{ce}}=40.81 \mathrm{~m} / \mathrm{min}$

$\rightarrow \mathrm{D}=20 \mathrm{~mm}, \mathrm{~V}_{\mathrm{ce}}=39.00 \mathrm{~m} / \mathrm{min}$ $\because \mathrm{m}=1.9, \mathrm{~d}=8, \quad \mathrm{~V}_{\mathrm{co}}=138 \mathrm{~m} / \mathrm{min}$

$\leftarrow \mathrm{m}=2.4, \mathrm{~d}=10, \mathrm{v}_{\mathrm{co}}=123 \mathrm{~m} / \mathrm{min}$

$\multimap \mathrm{m}=2.9, \mathrm{~d}=13, \mathrm{~V}_{\mathrm{co}}=110 \mathrm{~m} / \mathrm{min}$

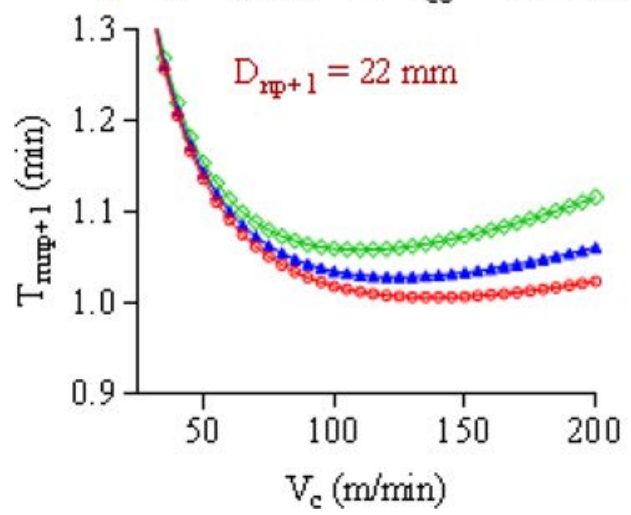

$\because \mathrm{m}=1.9, \mathrm{~d}=8, \quad \mathrm{~V}_{\mathrm{ce}}=55 \mathrm{~m} / \mathrm{min}$

$\rightarrow \mathrm{m}=2.4, \mathrm{~d}=10, \mathrm{~V}_{\mathrm{ce}}=50 \mathrm{~m} / \mathrm{min}$

$\rightarrow \mathrm{m}=2.9, \mathrm{~d}=13, \mathrm{~V}_{\mathrm{ce}}=41 \mathrm{~m} / \mathrm{min}$

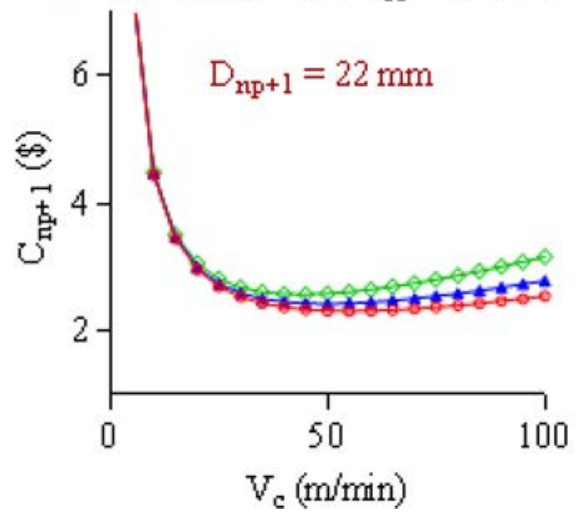


Fig. 13 Cutting time and cost variation for drilling the final diameter $D_{\mathrm{np}+1}\left(D_{\mathrm{np}+1}=30 \mathrm{~mm}\right)$

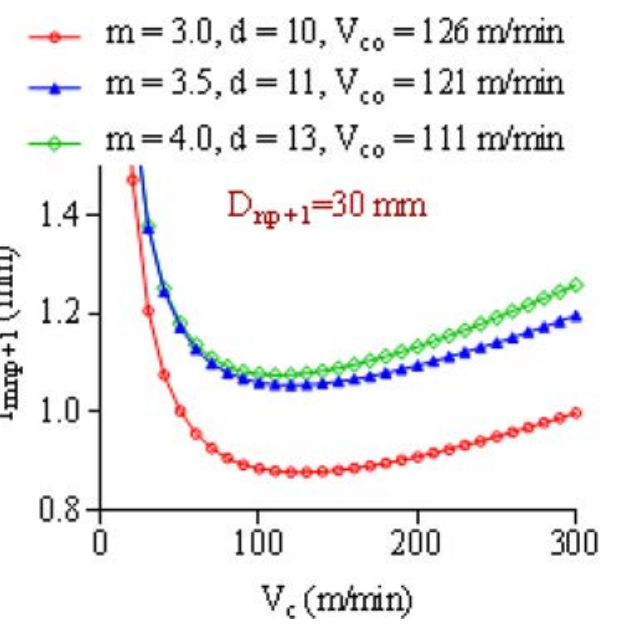

$\rightarrow \mathrm{m}=3.0, \mathrm{~d}=10, \mathrm{~V}_{\mathrm{ce}}=37 \mathrm{~m} / \mathrm{min}$
$\multimap \mathrm{m}=3.5, \mathrm{~d}=11, \mathrm{v}_{\mathrm{ce}}=35 \mathrm{~m} / \mathrm{min}$
$\multimap \mathrm{m}=4.0, \mathrm{~d}=13, \mathrm{v}_{\mathrm{ce}}=33 \mathrm{~m} / \mathrm{min}$

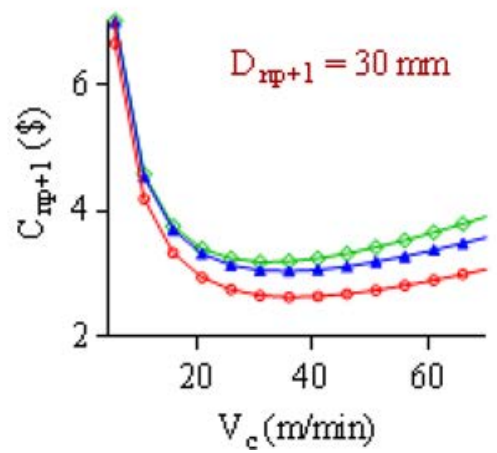

Table 8 Calculated values using developed models (the italicized values are the economical data)

\begin{tabular}{|c|c|c|c|c|c|c|c|c|c|c|}
\hline$D_{\mathrm{np}+1}(\mathrm{~mm})$ & $m$ & $d_{\mathrm{j}}(\mathrm{mm})$ & $D_{\mathrm{j}}(\mathrm{mm})$ & $V_{\text {cej }}(\mathrm{m} / \mathrm{min})$ & $f_{\mathrm{jc}}(\mathrm{mm} / \mathrm{rev})$ & $V_{\text {cmaxj }}(\mathrm{m} / \mathrm{min})$ & $V_{\text {cadj }}(\mathrm{m} / \mathrm{min})$ & $V_{\mathrm{cj}}(\mathrm{m} / \mathrm{min})$ & $C_{\mathrm{j}}(\$)$ & $C(\$)$ \\
\hline \multirow[t]{6}{*}{22} & 1.9 & 14 & 14 & 58.04 & 0.145 & 504.54 & 791.68 & 58.04 & 2.42 & 4.74 \\
\hline & & 8 & 22 & 55 & 0.261 & 666.22 & 1244.07 & 55 & 2.32 & \\
\hline & 2.4 & 12 & 12 & 71.31 & 0.119 & 668.47 & 678.58 & 71.31 & 2.20 & 4.63 \\
\hline & & 10 & 22 & 50 & 0.261 & 532.50 & 1244.07 & 50 & 2.43 & \\
\hline & 2.9 & 9 & 9 & 80.80 & 0.082 & 1129.13 & 508.93 & 80.80 & 2.14 & 4.73 \\
\hline & & 13 & 22 & 44 & 0.261 & 409.18 & 1244.07 & 44 & 2.58 & \\
\hline \multirow[t]{7}{*}{30} & 3 & 6 & 6 & 98.03 & 0.056 & 2169.95 & 339.29 & 98.03 & 1.80 & 6.60 \\
\hline & & 14 & 20 & 46 & 0.243 & 392.10 & 1130.97 & 46 & 2.15 & \\
\hline & & 10 & 30 & 37 & 0.331 & 480.17 & 1696.46 & 37 & 2.63 & \\
\hline & 3.5 & 19 & 19 & 41 & 0.234 & 274.01 & 1074.42 & 41 & 2.62 & 5.67 \\
\hline & & 11 & 30 & 35 & 0.331 & 436.36 & 1696.46 & 35 & 3.04 & \\
\hline & 4 & 17 & 17 & 44.01 & 0.184 & 356.01 & 961.32 & 44.01 & 2.74 & 5.92 \\
\hline & & 13 & 30 & 33 & 0.331 & 368.98 & 1696.46 & 33 & 3.18 & \\
\hline
\end{tabular}

Fig. 14 Total cost variation with the coefficient $m$

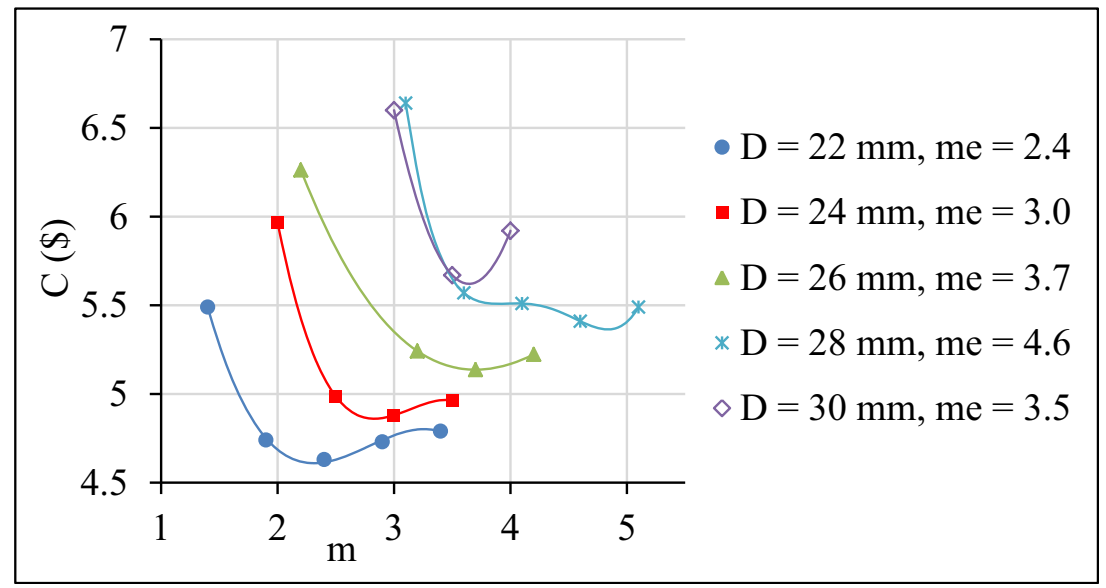




\section{Conclusion}

In this paper, a model of pre-drill diameter optimization in high-speed peck drilling cycle G83 is proposed. The developed algorithm of optimization provides a precise estimation of pre-drill diameter that leads to the minimum machining cost. It based on a pre-hole diameter model taking into account the geometric constraints of pre-drill. The cycle time is calculated used a feed rate model which is validated by an experimental study.

The pre-hole optimization is reached in two steps. In the first step, the economical cutting speed for each drilling diameter is determined considering the limitations and machine tool constraints, and in the second step, the optimal pre-drill diameter that leads to the minimal cutting cost are predicted. The results of this paper have shown that the economical process in peck drilling cycle G83 is obtained with the minimum number of pre-drill diameters, and it is due to the fact of the high cost of the machine.

Funding The work is carried through the support and funding allocated to the Unit of Mechanical and Materials Production Engineering (UGPMM / UR17ES43) by the Tunisian Ministry of Higher Education and Scientific Research.

\section{References}

1. Kim J, Dornfeld DA (2001) Cost estimation of drilling operations by a Drilling Burr Control Chart and Bayesian statistics. J Manuf Syst 20:89-97. https://doi.org/10.1016/S0278-6125(01)80032-7

2. Kim D, Ramulu M (2004) Drilling process optimization for graphite/bismaleimide-titanium alloy stacks. Compos Struct 63:101114. https://doi.org/10.1016/S0263-8223(03)00137-5

3. Iacob M, Blăjină O, Vlase A (2015) Model for economic optimization of the tool life and the cutting speed at drilling of the steel X5CrNiMo17-12-2. Appl Mech Mater 809-810:63-68. https://doi. org/10.4028/www.scientific.net/AMM.809-810.63

4. Shunmugam MS, Bhaskara Reddy SV, Narendran TT (2000) Optimal selection of parameters in multi-tool drilling. J Mater
Process Technol 103:318-323. https://doi.org/10.1016/S09240136(00)00500-8

5. Debongnie J-F. Usinage. CEFAL 2006; ISBN10:2-87130-234-0

6. Guiotoko EH, Aoyama H, Sano N (2017) Optimization of hole making processes considering machining time and machining accuracy. J Adv Mech Des Syst Manuf 11. https://doi.org/10.1299/ jamdsm.2017jamdsm0048

7. Othmani R, Hbaieb M, Bouzid W (2011) Cutting parameter optimization in NC milling. Int J Adv Manuf Technol 54:1023-1032. https://doi.org/10.1007/s00170-010-3017-4

8. Pessoles X, Landon Y, Rubio W (2010) Kinematic modelling of a 3 -axis $\mathrm{NC}$ machine tool in linear and circular interpolation. Int $\mathrm{J}$ Adv Manuf Technol 47:639-656

9. Gassara B, Baili M, Dessein G, Hbaieb M, Saï WB (2013) Feed rate modeling in circular-circular interpolation discontinuity for highspeed milling. Int J Adv Manuf Technol 65:1619-1634. https://doi. org/10.1007/s00170-012-4284-z

10. Islam MN, Boswell B, Ginting Y (2016) Effects of canned cycles and cutting parameters on hole quality in cryogenic drilling of aluminum 6061-6T. Int J Chem Mol Nucl Mater Metall Eng 10

11. Krar SF, Amand JVS, Oswald JW (1983) Machine tool operations, 1st edn. McGraw-Hill Science/Engineering/Math, Lake Forest

12. Xavier LF, Elangovan D (2013) Effective parameters for improving deep hole drilling process by conventional method - a review. Int J Eng Res Technol (IJERT) 2

13. Dietrich R, Garsaud D, Gentillon S (1981) Précis de méthodes d'usinage : méthodologie, production et normalisation. AFNOR; ISBN 2-12-355341-7

14. Gara S, Bouzid W, Amar MB, Hbaieb M (2009) Cost and time calculation in rough NC turning. Int J Adv Manuf Technol 40: 971-981. https://doi.org/10.1007/s00170-008-1417-5

15. Juan H, Yu SF, Lee BY (2003) The optimal cutting-parameter selection of production cost in HSM for SKD61 tool steels. Int J Mach Tools Manuf 43:679-686. https://doi.org/10.1016/S0890-6955(03) 00038-5

16. Ke F, Ni J, Stephenson DA (2006) Chip thickening in deep-hole drilling. Int J Mach Tools Manuf 46:1500-1507. https://doi.org/10. 1016/j.jimachtools.2005.09.022 